\title{
Interactive comment on "Characterization and Correction of OMPS Nadir Mapper Measurements for Ozone Profile Retrievals” by Juseon Bak et al.
}

\section{Anonymous Referee \#2}

Received and published: 13 October 2017

General comments and recommendation: This paper demonstrates the need for better retrieving tropospheric ozone from space-borne instrument, OMPS Nadir Mapper. Out of 3 OMPS sensors, the authors explained why OMPS NM is the most suitable for this. More detail description on the retrieval algorithm has been demonstrated on OMI instrument (Liu et al 2010). In this paper, the authors focused on better optimizing OMPS NM L1B measurements by introducing additional tuning methods.

This is a very well-written and well-structure paper and is highly relevant to the community. I only have several technical questions/criticisms.

Specific comments: 1. p2 in the Introduction: Line 53-54: I could only find one reference for Huang et al 2017 in the Reference. 
2. Fig 2c.1: It'd be nice to have shown scaling factor on the second Y-axis, as shown in Fig 2a.1 and 2b.1

AMTD

3. p10, in Soft Calibration Line 296: Figure 5 compares out preliminary tropospheric and stratospheric ozone column retrievals with collocated OMI retrievals... Can you elaborate more on how you collocated OMI and OMPS in this case?

4. p11 in Common Mode Correction You did not have CMC mentioned anywhere in the context, but Figure 10 and 11 use with CMC and without CMC experiments

5. p13 where you have comparison between Fig 15a and Fig 7b. Maybe it is just the color scheme that gives visual illusion. I found the higher value in pinkish color off west Atlantic shown in Fig. 7b, whereas in Fig 15a the max value seems to be shifted to east side of Atlantic in Fig 15a and it seems there is a strong gradient in Fig 15 in the middle of Atlantic.

Interactive comment on Atmos. Meas. Tech. Discuss., doi:10.5194/amt-2017-298, 2017.

Interactive

comment 